\title{
Role of RpoS in Stress Tolerance and Environmental Fitness of the Phyllosphere Bacterium Pseudomonas fluorescens Strain 122
}

\author{
Virginia O. Stockwell, Kevin Hockett, and Joyce E. Loper
}

First, second, and third authors: Department of Botany and Plant Pathology, Oregon State University, Corvallis 97331; and third author: U.S. Department of Agriculture-Agricultural Research Service, Horticultural Crops Research Laboratory, 3420 NW Orchard Avenue, Corvallis, OR 97330.

Current address of K. Hockett: Department of Microbial and Plant Biology, University of California, Berkeley.

Accepted for publication 20 January 2009.

\begin{abstract}
Stockwell, V. O., Hockett, K., and Loper, J. E. 2009. Role of RpoS in stress tolerance and environmental fitness of the phyllosphere bacterium Pseudomonas fluorescens strain 122. Phytopathology 99:689-695.

Bacteria living epiphytically on aerial plant surfaces encounter severe and rapidly fluctuating environmental conditions, and their capacity to withstand environmental stress contributes to epiphytic fitness. The stationary phase sigma factor RpoS is a key determinant in stress response of gram-negative bacteria, including Pseudomonas spp. This study focused on the role of RpoS in stress response and epiphytic fitness

and an oxidative environment. While significant, the difference in stress response between an rpoS mutant and the parental strain was less for strain 122 than for the rhizosphere bacterium P. fluorescens Pf-5. No consistent influence of RpoS on epiphytic population size of strain 122 on pear or apple flowers or leaves was observed in field trials. These data may indicate that $P$. fluorescens occupies protected microsites on aerial plant surfaces where the bacteria escape exposure to environmental stress, or that redundant stress-response mechanisms are operating in this bacterium, thereby obscuring the role of RpoS in epiphytic fitness of the bacterium.
\end{abstract} of Pseudomonas fluorescens strain 122 on aerial plant surfaces. RpoS had a significant role in the response of the phyllosphere bacterium $P$. fluorescens 122 to stresses imposed by desiccation, UV irradiation, starvation,
Additional keywords: floral surfaces.
Fluorescent pseudomonads are ubiquitous inhabitants of plant surfaces, including flowers, leaves, and roots. In these natural environments, bacteria can be exposed to environmental stresses imposed by rapid changes in temperature, water availability, osmotic potential, and nutrient availability (2). The capacity to survive environmental stress is an important fitness factor for Pseudomonas spp. inhabiting the phyllosphere (15), and the stationary phase sigma factor $\operatorname{RpoS}\left(\sigma^{S}\right)$ is required for optimal stress response in many strains of Pseudomonas spp. (5,10,13,16$18,23,26,30,31)$. The sigma subunit is a dissociable protein of the eubacterial RNA polymerase holoenzyme responsible for promoter specificity in the initiation of transcription (7). Under conditions of cellular starvation, $\sigma^{\mathrm{S}}$ accumulates, binds, and directs the RNA polymerase holoenzyme to many genes with diverse functions, including stress response $(6,7,20,28)$. RpoS is not the only sigma factor contributing to stress response of Pseudomonas spp., however, and $\sigma^{22}$ and $\sigma^{54}$ provide examples of other sigma factors that contribute to survival of desiccation, osmotic, or starvation stress, at least in some strains $(11,22,27)$

Our research program focuses on biological control strains of Pseudomonas fluorescens, including the rhizosphere strain Pf-5 and the epiphytic strain A506. In previous studies, we discovered that the role of RpoS in stress response differs markedly between the two strains. RpoS plays a major role in multiple stress responses of Pf- 5 and also contributes to fitness of the bacterium in the rhizosphere of plants grown in dry soils (30). In contrast,

Corresponding author: V. O. Stockwell

E-mail address: stockwev@science.oregonstate.edu

\section{doi:10.1094/PHYTO-99-6-0689}

This article is in the public domain and not copyrightable. It may be freely reprinted with customary crediting of the source. The American Phytopathological Society, 2009.
RpoS has a negligible role in stress response of A506 and no detectable influence on the fitness of the strain on aerial plant surfaces (4). The two strains also differ in the relative stress response of cells in the exponential versus stationary phase of culture. Stationary-phase cells of Pf-5 are far more resistant than exponentially-growing cells to multiple stresses $(26,30)$, as is typical of other strains of Pseudomonas spp. $(10,13,16)$. In contrast, cells of A506 in these phases of the bacterial growth cycle exhibit little difference in stress resistance (4). Furthermore, the rpoS of strain A506 has a frameshift mutation which renders it nonfunctional (4). Strain A506 may represent an anomaly from a conserved mechanism of stress response in Pseudomonas spp., or it may provide an example of previously undescribed variation in molecular control of stress response in this group of bacteria.

This study was initiated to complement earlier investigations into the role of RpoS in stress response of plant-associated Pseudomonas spp. An rpoS mutant of the epiphytic strain Pseudomonas sp. 122 was derived and compared with the parental strain for stress response and epiphytic fitness on apple and pear in seven replicated field trials. Results indicate that $r p o S$ has a minor role in stress response or environmental fitness of strain 122, as was observed previously in the epiphytic bacterium $P$. fluorescens strain A506. The results of this study indicate that molecular factors controlling stress response and environmental fitness differ among strains of Pseudomonas spp.

\section{MATERIALS AND METHODS}

Bacterial strains and growth conditions. The phyllosphere bacterium Pseudomonas sp. strain 122 was a gift from Steven Lindow (University of California at Berkeley). Strain 122 is resistant to rifampicin at $100 \mu \mathrm{g} / \mathrm{ml}$ by spontaneous mutation (S. Lindow, personal communication). Strain 122 was identified as $P$. 
fluorescens based upon the following characteristics: production of a fluorescent pigment on King's medium B (KMB) (12), oxidase negative, gelatin hydrolysis, and utilization of trehalose, meso-inositol, and DL-arabinose as carbon sources (3). The nucleotide sequence of the 16S rDNA of strain 122 (GenBank accession no. EU003535) indicates that the strain fits within the $P$. fluorescens intrageneric cluster (8). The GenBank accession number for the sequence of rpoS of $P$. fluorescens strain 122 is EU147502. The rhizosphere bacterium $P$. fluorescens Pf-5, the rpoS mutant JL3985, and rifampicin-resistant derivatives of Pf-5 (Pf-5R) and of JL3985 have been described previously (30).

$P$. fluorescens was cultured at $27^{\circ} \mathrm{C}$ on Luria-Bertani (LB) medium (24) or KMB. Antibiotics (Sigma-Aldrich, St. Louis) were used in the following concentrations: cycloheximide at $50 \mu \mathrm{g} / \mathrm{ml}$, kanamycin at $50 \mu \mathrm{g} / \mathrm{ml}$, or rifampicin at $100 \mu \mathrm{g} / \mathrm{ml}$.

Derivation of an rpoS mutant of strain 122 through allelic exchange mutagenesis. A Tn5 insertion was introduced into rpoS of 122 via allelic exchange mutagenesis with plasmid pJEL1995, which contains rpoS::Tn5 and flanking regions from the Pf-5 genome, as described before (30). rpoS disruption and plasmid loss were confirmed by Southern analysis using pJEL1995 as a probe. One derivative of strain 122 having the expected Tn5 insertion in $\operatorname{rpoS}$ was selected for further analysis.

Growth rate determinations. Bacterial strains were grown at $27^{\circ} \mathrm{C}$ with shaking $(200 \mathrm{rpm})$ in replicate test tubes containing $5 \mathrm{ml}$ of LB or KMB. Over $36 \mathrm{~h}$, the optical density of cultures was measured at $\lambda 600 \mathrm{~nm}$ with a spectrophotometer. This experiment was repeated twice.

Culture and harvest of cells used for stress response tests. Strains of $P$. fluorescens were grown in $\mathrm{LB}$ at $27^{\circ} \mathrm{C}$ with shaking overnight. Then, $50 \mu \mathrm{l}$ of an overnight culture was inoculated into $5 \mathrm{ml}$ of fresh LB broth in a culture tube and grown under the same conditions for 4 to $5 \mathrm{~h}$ (exponential-phase cells) or 16 to $24 \mathrm{~h}$ (stationary-phase cells). Bacterial cells were collected by centrifugation $(5,000 \times \mathrm{g}, 3 \mathrm{~min})$, washed twice in $10 \mathrm{mM}$ phosphate buffer ( $\mathrm{pH} 7.0)$, and suspended in buffer to a final optical density of $0.1(\lambda 600 \mathrm{~nm})\left(\approx 1 \times 10^{8} \mathrm{CFU} / \mathrm{ml}\right)$. Three replicate cultures of each strain were evaluated in the stress response tests and every experiment was repeated at least twice.

Freezing stress. Tolerance to freezing was assessed by the method of Stockwell and Loper (30). Briefly, bacterial suspensions $(100 \mu \mathrm{l})$ were transferred to sterile microfuge tubes and held at -20 or $-80^{\circ} \mathrm{C}$ for $12 \mathrm{~h}$. To thaw samples rapidly, $900 \mu \mathrm{l}$ of $10 \mathrm{mM}$ phosphate buffer $\left(\approx 20^{\circ} \mathrm{C}\right)$ was added to each tube immediately after it was removed from the freezer. Samples were vortexed for $30 \mathrm{~s}$ and culturable cells in the suspensions were enumerated on KMB agar.

Starvation stress. The effect of starvation on culturability was assessed by incubating stationary-phase cells in $1 \mathrm{mM}$ phosphate buffer ( $\mathrm{pH} \mathrm{7)}$ and $0.8 \%$ saline (wt/vol) with agitation $(200 \mathrm{rpm})$ at $27^{\circ} \mathrm{C}(30)$. Samples were removed periodically and dilutions were spread onto KMB agar for enumeration.

Oxidative stress. Cells were suspended in $10 \mathrm{mM}$ phosphate buffer ( $\mathrm{pH}$ 7.0) and $\mathrm{H}_{2} \mathrm{O}_{2}$ was added to a final concentration of
$15 \mathrm{mM}$ (26). The suspensions were incubated with shaking at $27^{\circ} \mathrm{C}$ and the number of culturable cells determined periodically over 80 min by spreading diluted samples onto KMB.

Ultraviolet irradiation. Tolerance to ultraviolet irradiation was measured by methods described by Whistler and associates (33). Briefly, dilutions of cell suspensions were spread onto KMB and immediately exposed to UV irradiation $(\lambda 254 \mathrm{~nm})$ at doses up to $86 \mathrm{~J} \mathrm{~m}^{-2}$. After exposure to UV irradiation, plates were incubated in darkness for 3 days and then colonies were counted.

Desiccation stress. Bacterial cells were suspended in sterile distilled water $\left(10^{8} \mathrm{CFU} / \mathrm{ml}\right)$ and $10 \mu \mathrm{l}$ was placed on $1 \mathrm{~cm}^{2}$ of sterilized Whatman no. 1 filter paper. The filters were suspended on wire supports over a saturated solution of $\mathrm{NaCl}$ in sealed containers held at $25^{\circ} \mathrm{C}$ to maintain a relative humidity of $75 \%$ (14). Control sets of filters were suspended in chambers containing water and $100 \%$ relative humidity. Periodically, filters were removed, placed in $10 \mathrm{mM}$ phosphate buffer ( $\mathrm{pH} 7.0)$, and sonicated for $3 \mathrm{~min}$, prior to spreading dilutions on KMB.

Data analysis. For analysis of data from laboratory experiments assessing stress tolerance, survival ratios were calculated by dividing the observed population at a sample point by the initial population. Survival ratios were $\log _{10}$ transformed prior to statistical analyses. Population data were subjected to mean separation by Fisher's protected least significant difference test at $P=0.05$ using the analysis of variance procedure of Statistical Analysis Systems (SAS Institute, Cary, NC).

Field studies. Weather data for all field trials are summarized in Table 1.

The population sizes of strain 122 and the $\operatorname{rpoS}$ mutant were estimated on flowers of pear (Pyrus communis L. 'Bartlett' or 'Bosc') or apple (Malus $\times$ domestica Borkh., 'Rome Beauty') in experimental orchards at the Oregon State University, Botany and Plant Pathology Field Laboratory near Corvallis, OR in 1997. An aqueous suspension of each strain $\left(1 \times 10^{8} \mathrm{CFU} / \mathrm{ml}\right)$ was sprayed on blossom clusters of five (Bartlett), three (Bosc), and four (Rome Beauty) replicate trees (at the 50 to $70 \%$ bloom stage) arranged in a randomized complete block design. At each sampling date, culturable bacterial populations were estimated from 10 flowers harvested from each tree using described methods (29). Pseudomonas agar F (PAF, Difco Laboratories, Detroit) with cycloheximide at $50 \mu \mathrm{g} / \mathrm{ml}$ and rifampicin at $50 \mu \mathrm{g} / \mathrm{ml}$ was used for selective recovery of strain 122, and PAF amended with cycloheximide at $50 \mu \mathrm{g} / \mathrm{ml}$ and kanamycin at $50 \mu \mathrm{g} / \mathrm{ml}$ was used for selective recovery of the rpoS mutant. Mean population size of bacterial strains and standard error were calculated by averaging the logarithm (base 10) of population values. The detection limit was $1 \times 10^{2} \mathrm{CFU} /$ flower. When the bacterial population size in a sample was below detection, then a value of $1 \mathrm{CFU}$ below the detection limit was assigned that sample.

The survival of 122, Pf-5R, and rpoS mutants of each strain was evaluated on leaves of pear (cv. Bartlett) and apple (cv. Red Delicious). Bacterial suspensions were prepared to a concentration of $1 \times 10^{10} \mathrm{CFU} / \mathrm{ml}$ and applied, as described above, to leaves on marked branches of five replicate trees per treatment

TABLE 1. Environmental conditions and sampling dates for orchard trials

\begin{tabular}{|c|c|c|c|c|c|c|}
\hline \multirow[b]{3}{*}{ Cultivar, tissue } & \multirow[b]{3}{*}{ Treatment $^{\mathrm{a}}$} & \multicolumn{5}{|c|}{ Environmental conditions ${ }^{\mathrm{b}}$} \\
\hline & & \multicolumn{3}{|c|}{ Temperature $\left({ }^{\circ} \mathrm{C}\right)$} & \multirow[b]{2}{*}{ Days with rain ${ }^{c}$} & \multirow[b]{2}{*}{ Total rainfall $(\mathrm{mm})$} \\
\hline & & Mean daily & Maximum & Minimum & & \\
\hline Pear, Bartlett, flowers & 8 April & 10.2 & 22.7 & 0.7 & 11 of 15 & 71 \\
\hline Pear, Bosc, flowers & 13 April & 11.1 & 22.7 & 3.3 & 9 of 11 & 68 \\
\hline Apple, Rome Beauty, flowers & 5 May & 16.3 & 31.1 & 5.7 & 1 of 7 & 2 \\
\hline Pear, Bartlett, leaves & 8 August & 21.8 & 35.3 & 8.6 & 0 of 6 & 0 \\
\hline Apple, Red Delicious, leaves & 13 August & 19.7 & 33.6 & 10.1 & 1 of 9 & 0.5 \\
\hline
\end{tabular}

a Date of application of bacteria.

b Environmental conditions recorded from time of application of bacteria to final sample.

${ }^{c}$ Number of days with measurable rain of the total number of days of the sampling period. 
arranged in a randomized complete block design. Four h after application and periodically over a week, 10 leaves were removed from marked branches and placed individually in resealable plastic bags. Leaf samples were placed in $10 \mathrm{ml}$ of sterile phosphate buffer and sonicated. The sample and dilutions were spread on antibiotic-amended media described above to enumerate the population size of each strain. The detection limit was $1 \times 10^{2}$ $\mathrm{CFU} /$ leaf. If bacteria were not detected from a sample, then a value of $1 \mathrm{CFU}$ below the detection limit was assigned.

\section{RESULTS}

Influence of $\operatorname{rpoS}$ on growth and stress tolerance of strain 122. The growth rates of strain 122 and the rpoS derivative in LB and KMB broth were similar (data not shown).

The capacities of strain 122 and the rpoS mutant to survive exposure to environmental stresses were compared to determine the role of rpoS in stress tolerance of this bacterium. Because of the established role of rpoS in stress response of $P$. fluorescens strain Pf-5 (30), this bacterium was included as a control.

Strain 122 and its $\operatorname{rpoS}$ mutant tolerated freezing and starvation stresses. Stationary-phase cells of strain 122 and the rpoS mutant were significantly more tolerant of freezing at $-80^{\circ} \mathrm{C}$ than were exponential-phase cells of these bacteria (Fig. 1A and B) but the rpoS mutant did not differ significantly from 122 in the capacity to survive freezing. Strain 122 survived freezing to a level similar to that of strain Pf-5, for which rpoS has a significant role in freezing tolerance by stationary-phase cells (Fig. 1). Strain 122 and its rpoS mutant tolerated starvation conditions while suspended in sterile, aerated, phosphate-buffered saline; culturable populations decreased below the initial population size only on day 18 (Fig. 2A). On three sampling dates, significant differences between the population size of strain 122 and its rpoS mutant were observed, but these differences were small in magnitude compared with those separating Pf-5 and its rpoS mutant (Fig. 2B).

The rpoS mutant of 122 was more sensitive than the parental strain to oxidative stress, UV irradiation, and desiccation stress. Culturable populations of both Pf-5 and 122 decreased during exposure to hydrogen peroxide (Fig. 3) and cells in stationary phase were less sensitive to oxidative stress than cells in exponential phase. Whether in stationary or exponential phase, the
rpoS mutants were more sensitive to oxidative stress than their parental strains. For stationary-phase cells, the magnitude of the difference in sensitivity to oxidative stress between the $\operatorname{rpoS}$ mutant and its parental strain was greater for Pf-5 than for 122. RpoS also influenced UV sensitivity; stationary-phase cells of the rpoS

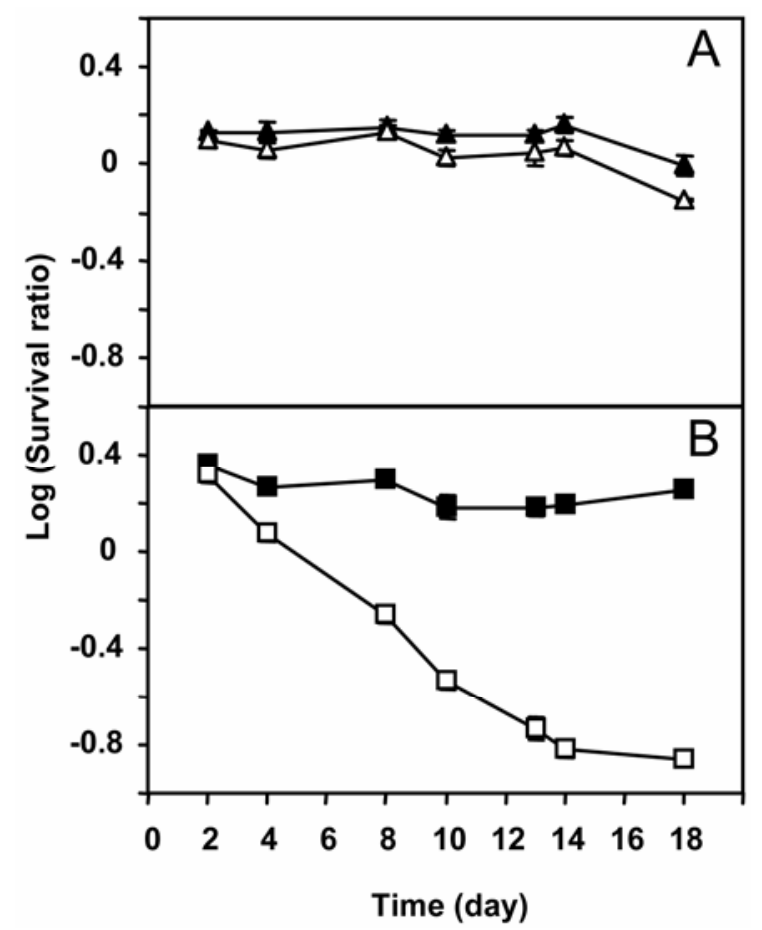

Fig. 2. Effect of an rpoS mutation on tolerance of starvation. Tolerance of starvation by cells of A, Pseudomonas fluorescens strain $122(\mathbf{A})$ and 122 $\operatorname{rpoS}(\Delta)$ and B, Pf-5 (ם) and Pf-5 rpoS $(\square)$ cultured in broth media until populations entered stationary phase. Washed cells were suspended in $0.8 \%$ $\mathrm{NaCl}$ in $1 \mathrm{mM}$ phosphate buffer and sampled periodically. Culturability is expressed as the logarithm of the survival ratio, which is the enumerated population suspended in buffered saline divided by the population in the initial sample. Vertical bars represent one standard error of the mean. The experiment was conducted five times; the results shown are from a representative experiment.

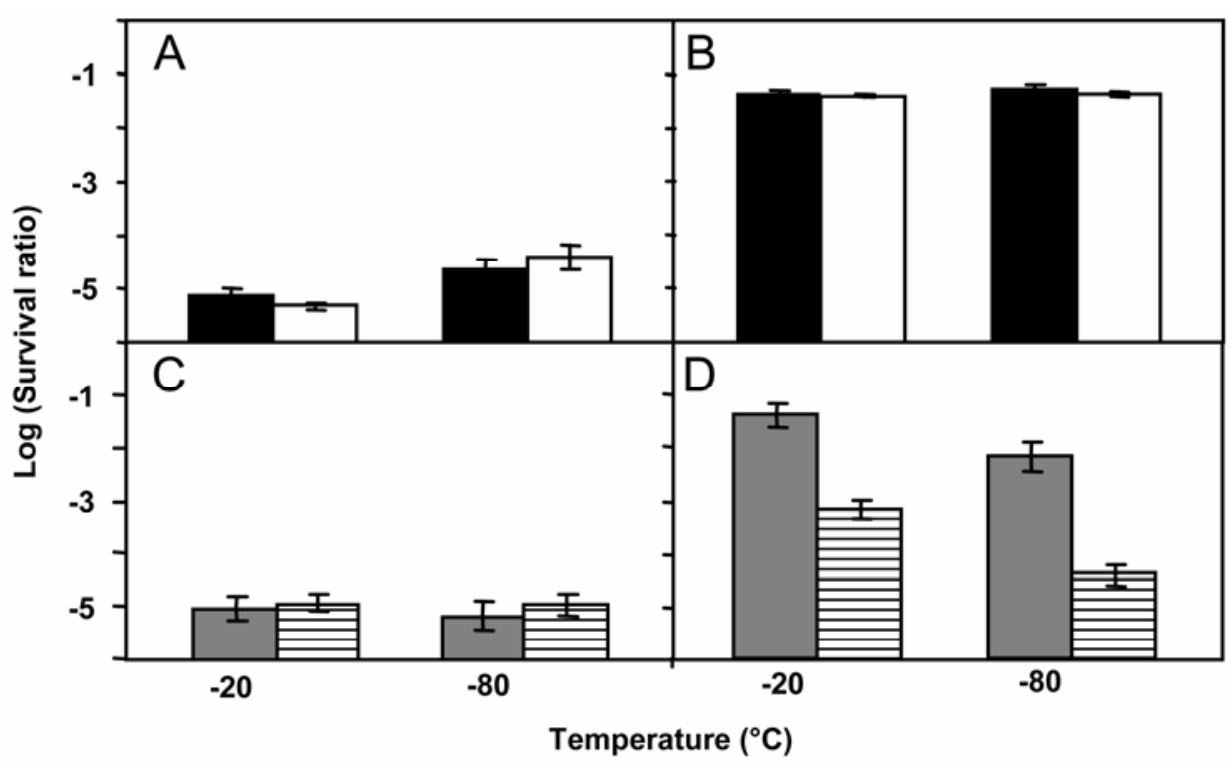

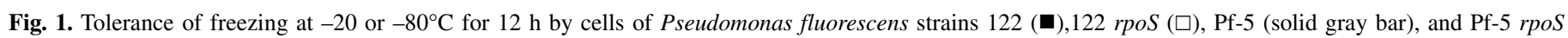

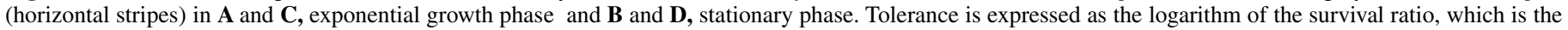

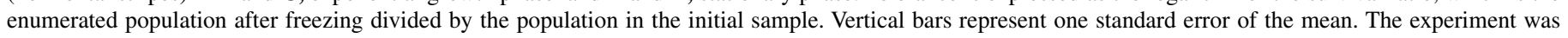
conducted five times; the results shown are from a representative experiment. 
mutants of strains 122 and Pf-5 were less tolerant of exposure to UV radiation than were stationary-phase cells of the respective parental strains (Fig. 4). Finally, exponential-phase cells of 122 were significantly more sensitive to drying at $75 \%$ relative humidity than were cells in stationary phase (Fig. 5). Whether in stationary or exponential phase, the rpoS mutant was more sensitive than the parental strain 122 to desiccation stress.

In strain 122, rpoS did not influence colonization of flowers or survival on leaves. On flowers of pear, strain 122 and its rpoS mutant established population sizes of $\approx 10^{5} \mathrm{CFU} /$ flower immediately after inoculation, and population sizes increased over the bloom period (Fig. 6A and B). Mean populations of the rpoS mutant were significantly greater than the wild-type strain at 8 days after inoculation on flowers of Bartlett pear and at 5 and 11 days after inoculation on Bosc pear. Initial population sizes of 122 and the rpoS mutant $\left(\approx 4 \times 10^{3} \mathrm{CFU} /\right.$ flower) on apple (Fig. 6C) were lower than initial populations on pear, perhaps because there was little rain during the apple field experiment (Table 1). On apple flowers, the mean population sizes of 122 and the rpoS mutant did not differ significantly (Fig. 6C), with both populations increasing over the bloom period.

On apple leaves, initial mean populations were $10^{7}$ to $10^{8} \mathrm{CFU} /$ leaf for each strain (Fig. 7A and B). Over 3 days, the mean population size of both 122 and its $r p o S$ mutant decreased to $10^{5} \mathrm{CFU} /$ leaf. By 9 days, the mean population size of these strains was $10^{4} \mathrm{CFU} /$ leaf. At each sample time, the population size of $122 \mathrm{did}$ not differ significantly from the rpoS mutant of 122 (Fig. 7A). On apple, mean populations of strain Pf-5R decreased to $5 \times 10^{3}$ CFU/leaf by 3 days and were detected at $6 \times 10^{2} \mathrm{CFU} /$ leaf 9 days after application (Fig. 7B). The population size of the rpoS mutant of Pf-5R decreased rapidly to $3 \times 10^{3} \mathrm{CFU} /$ leaf 1 day after application. The population sizes of Pf-5R and its $r p o S$ mutant were significantly different for the first 3 days after application to apple leaves.

On pear leaves, initial mean populations for all strains were $\approx 10^{5} \mathrm{CFU} /$ leaf (Fig. 7C and D); the lower initial population size on pear compared with apple leaves may be due to the smoother, waxy surface of pear leaves compared with apple leaves. On pear leaves, the mean population size of 122 and its rpoS mutant decreased to $\approx 2 \times 10^{2} \mathrm{CFU} /$ leaf within 2 days after application and did not differ significantly (Fig. 7C). The population size of Pf-5R also decreased on pear leaves to $\approx 6 \times 10^{2} \mathrm{CFU} /$ leaf (Fig. 7D). The rpoS mutant of Pf-5R exhibited a more rapid decrease in population size than the parental strain; at 1 and 2 days after application, the mean population sizes of the rpoS mutant of Pf-5R were significantly lower than the parental strain Pf-5R (Fig. 7D).

\section{DISCUSSION}

The stationary-phase sigma factor RpoS had a significant role in the response of the phyllosphere bacterium P. fluorescens 122 to stresses imposed by desiccation, UV irradiation, starvation, and an oxidative environment. These findings are consistent with

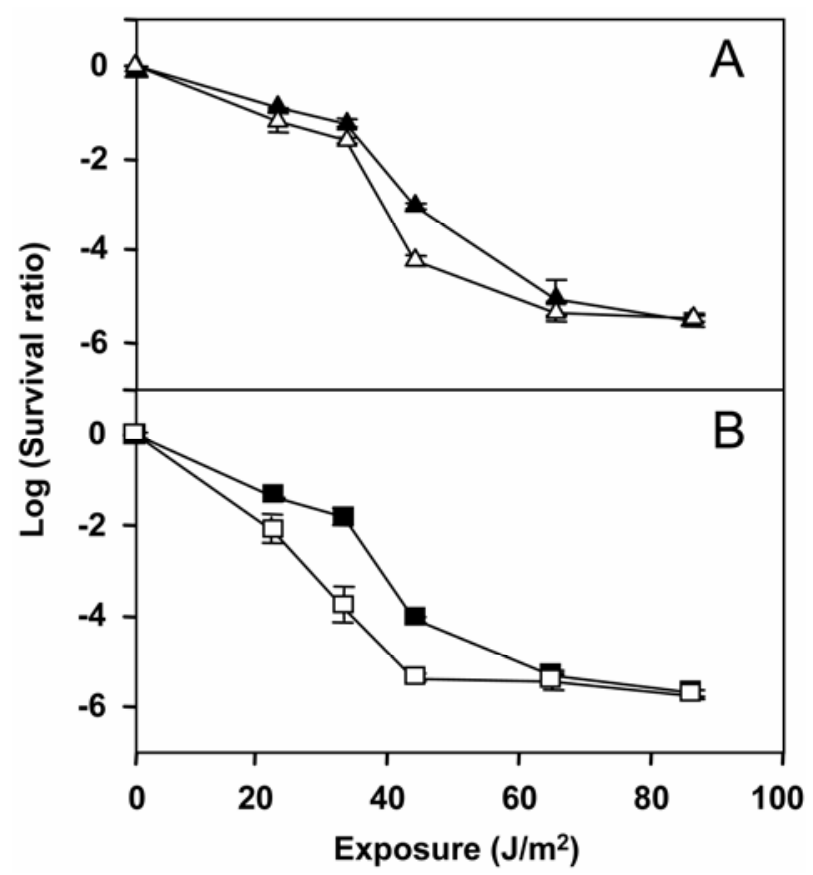

Fig. 4. Effect of an rpoS mutation on tolerance of UV irradiation. Tolerance of UV irradiation by stationary phase cells of $\mathbf{A}$, Pseudomonas fluorescens strain $122(\mathbf{\Delta})$ and $122 \operatorname{rpoS}(\Delta)$ and $\mathbf{B}$, Pf-5 (⿴) and Pf-5 rpoS ( $\square$ ). Washed cells were spread on media and immediately exposed to various doses of UV. Colonies were counted after a 3-day incubation period in the dark. Culturability is expressed as the logarithm of the survival ratio, which is the enumerated population after exposure to UV divided by the population that was not exposed. Vertical bars represent one standard error of the mean. The experiment was conducted four times; the results shown are from a representative experiment.

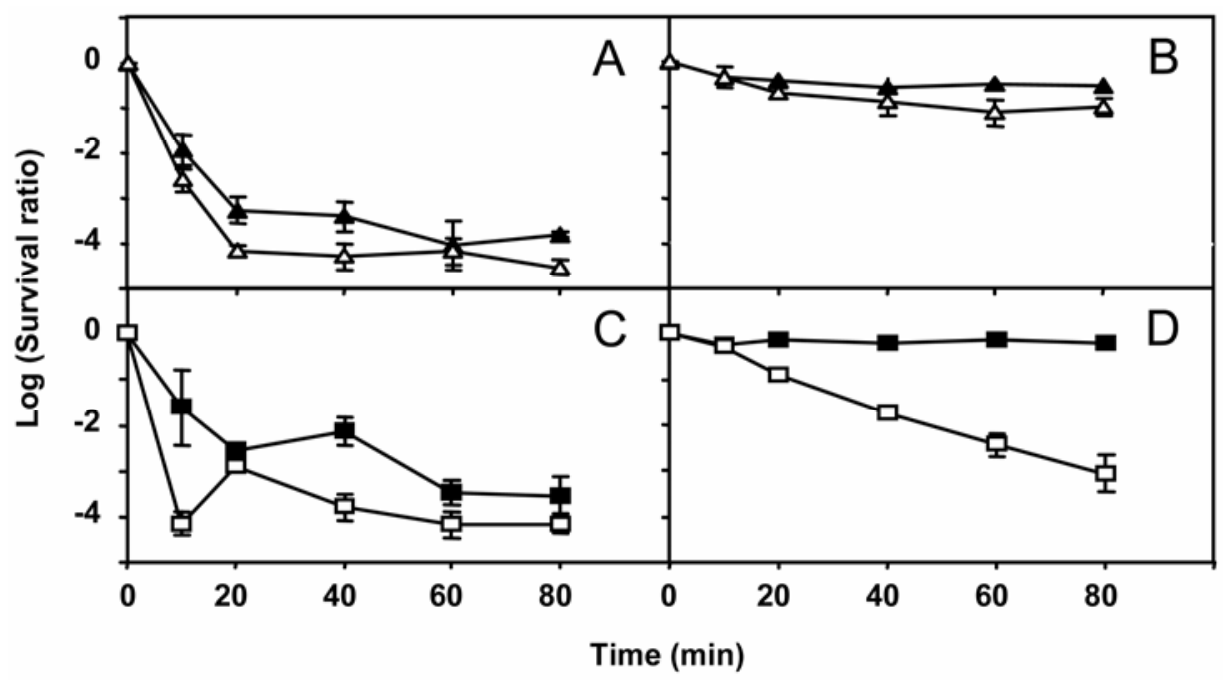

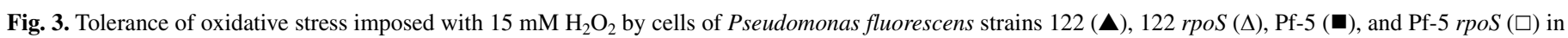

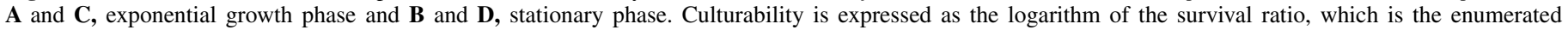

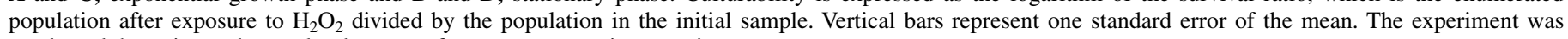
conducted three times; the results shown are from a representative experiment. 
previous reports of the positive role of RpoS in survival of other strains of P. fluorescens or Pseudomonas spp. exposed to desiccation (30), UV irradiation $(17,30)$, starvation $(10,23,26,31)$, and oxidative stress $(5,10,13,16,18,26,31)$. In contrast to previous findings with strain Pf-5 (30), however, RpoS did not have a significant role in the survival of strain 122 when exposed to freezing temperatures. Furthermore, differences in stress tolerance between the rpoS mutant and parental strain 122 were consistently smaller in magnitude than those of strain Pf-5 (30; this study). Thirty-four sigma factors have been identified in the genomes of P. fluorescens strain Pf-5 (21) and strain Pf0-1 (GenBank accession no. NC007492) and, although the functions of genes controlled by these sigma factors remain uncharacterized, at least two sigma factors other than RpoS are known to play a role in stress response of $P$. fluorescens. For example, the sigma factor $\mathrm{AlgU}$ (also called AlgT, RpoE, and $\sigma^{22}$ ), a key determinant of extra-

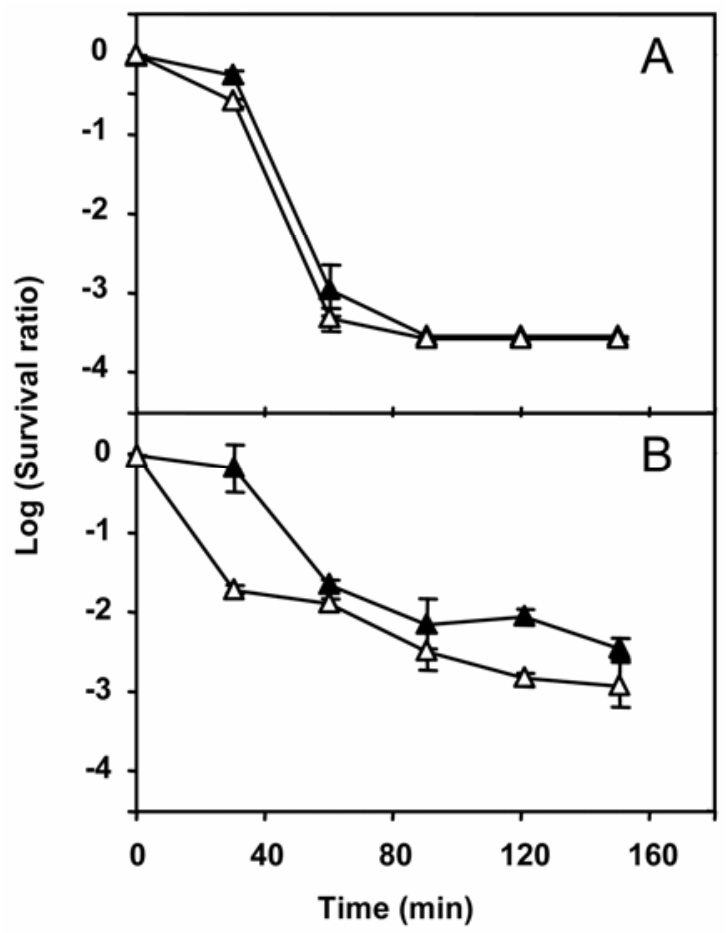

Fig. 5. Tolerance of desiccation by Pseudomonas fluorescens strain $122(\mathbf{A})$ and $122 \operatorname{rpoS}(\Delta)$ in $\mathbf{A}$, exponential growth phase and $\mathbf{B}$, stationary phase. Washed cells were place on sterile filter paper, exposed to $75 \%$ relative humidity, and sampled periodically. Culturability is expressed as the logarithm of the survival ratio, which is the enumerated population during exposure to $75 \%$ relative humidity divided by the population in the initial sample. Vertical bars represent one standard error of the mean. The experiment was conducted three times and the results shown are from a single representative experiment. cellular polysaccharide production, is required for optimal survival of $P$. fluorescens CHA0 when exposed to desiccation and osmotic stress (27). An rpoN mutant of CHA0 is also more sensitive than the parental strain to salt, indicating a role for $\sigma^{54}$ in osmotic stress (22). The relative importance of RpoS in stress response appears to differ among strains of $P$. fluorescens.

In replicated field trials, we detected no consistent influence of rpoS on the colonization of flowers of pear or apple by strain 122 . Because rpoS influenced stress response in strain 122, and plantassociated bacteria are thought to be exposed to harsh and fluctuating environmental conditions on aerial surfaces of field-grown plants, we were surprised that there were not larger differences in the population sizes established by 122 and an rpoS mutant in our field experiments. One possibility for the lack of effect of $r p o S$ on floral colonization is that the environmental stresses experienced by bacteria may be modulated by characteristics of these tissues. The primary site of colonization of floral tissues of pear and apple is the stigma. Pear and apple flowers bear "wet" stigmas whose surfaces are coated with moist, nutrient-rich exudates $(25,32)$. The exudates are thought to facilitate adhesion of pollen grains and osmoregulated germination of pollen on the stigmatic papillae (25). In addition to pollen grains, the stigmas of pear and apple also support growth of microbes, including $P$. fluorescens $(9,19)$. The population size of bacteria on stigmatic tissues of pear and apple often exceeds that on leaf surfaces when converted to the common unit of CFU/gram (9). Thus, on floral surfaces, $P$. fluorescens may occupy protected sites where it escapes exposure to environmental stress. Consequently, a functional $\operatorname{rpoS}$, which should improve the capacity of bacteria to survive environmental stress, may not be important for bacteria to colonize the relatively hydrated, nutrient-rich stigmas of flowers.

On leaf surfaces, protective sites for bacteria include the base of trichomes, wounds, and natural openings (1). In our experiments on survival of bacteria in the phyllosphere, the rpoS mutant of Pf-5 survived poorly compared with the parental strain, indicating that RpoS is important for epiphytic fitness of this strain. This is in agreement with two other studies, where a significant influence of RpoS on environmental fitness was observed only under conditions of environmental stress. A significant influence of RpoS on rhizosphere colonization by Pf-5 was observed primarily under conditions of desiccation stress; an rpoS mutant of Pf-5 did not survive as well as the wild-type strain in the rhizosphere of bean planted in dry soil, whereas differences in survival of the strains were sometimes less pronounced in moist soils. Similarly, an rpoS mutant of $P$. putida KT2440 was more sensitive than the wild-type strain to stress imposed by the toxic compound $m$-methylbenzoate in soil (23). The population size of the rpoS mutant declined more than those of the wild-type strain in soil amended with this compound. In contrast, soil populations of KT2440 derivatives containing the TOL plasmid, which confers $m$-methylbenzoate degradation, were stable in the soil re-

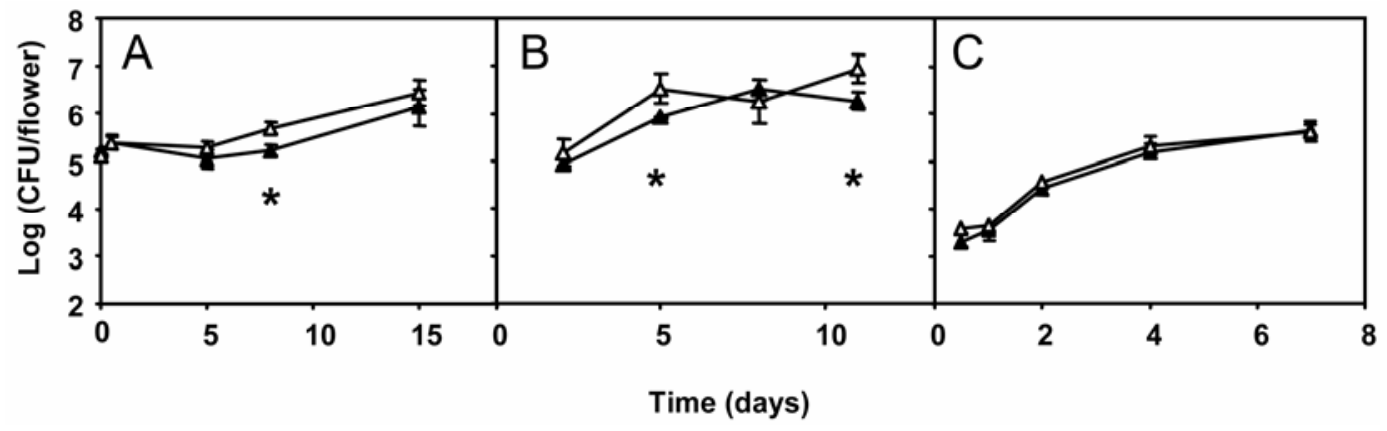

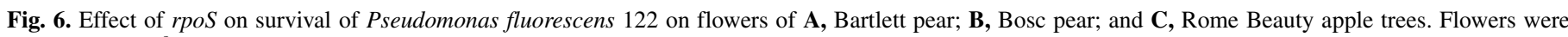

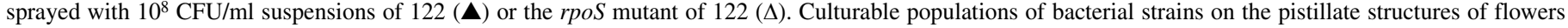

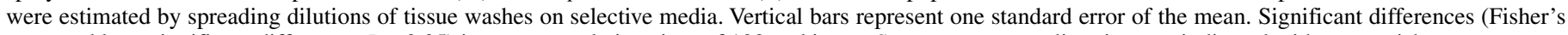
protected least significant difference, $P=0.05$ ) in mean population sizes of 122 and its $r p o S$ mutant at a sampling time are indicated with an asterisk. 


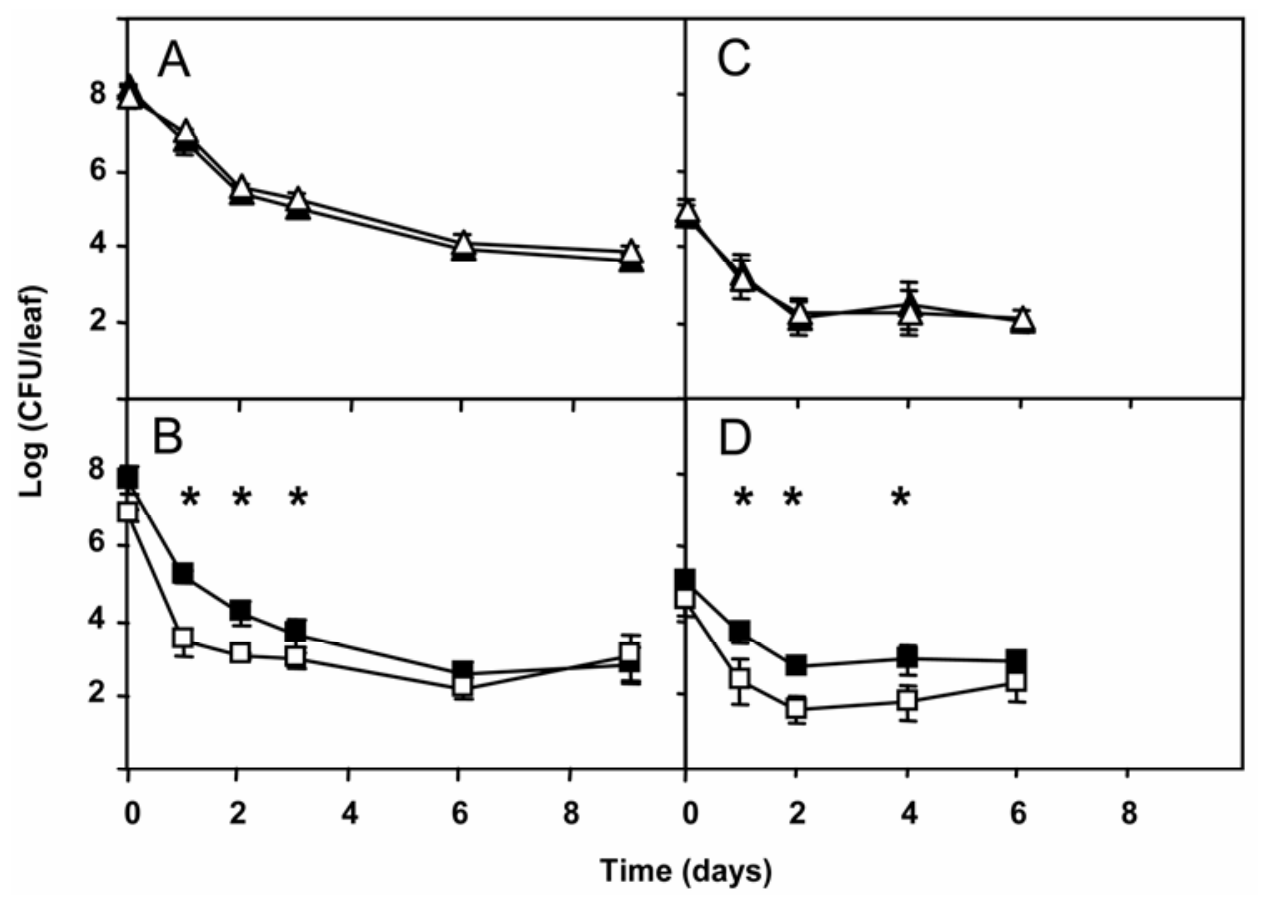

Fig. 7. Survival of Pseudomonas fluorescens strain $122(\mathbf{\Delta})$, its 122 rpoS $(\Delta), \operatorname{Pf}-5 \mathrm{R}(\mathbf{\square})$, and Pf-5R rpoS $(\square)$ on leaves of $\mathbf{A}$ and $\mathbf{B}$, Red Delicious apple and $\mathbf{C}$ and D, Bartlett pear trees in the field. Leaves were sprayed with bacterial suspensions of $10^{10} \mathrm{CFU} / \mathrm{ml}$. Culturable populations of bacterial strains on leaves were estimated by spreading dilutions of washes from individual leaves on selective media. Vertical bars represent one standard error of the mean. Significant differences (Fischer's protected least significant difference, $P=0.05$ ) in mean population sizes of Pf-5 and its $r p o S$ mutant at a sampling time are indicated with an asterisk; mean populations of 122 and its rpoS mutant did not differ significantly.

gardless of rpoS. The results from these previous studies indicate that the role of RpoS as a fitness factor of Pseudomonas spp. in the soil or rhizosphere is related in large part to its role in surviving stresses that the bacteria encounter in these habitats.

This study highlights a differential role of RpoS in the stress response and epiphytic survival of two strains of $P$. fluorescens: the rhizosphere inhabitant Pf-5 and the epiphytic strain 122. It is possible that the small but significant influence of $r p o S$ on stress response in strain 122, which is detectable in laboratory assays, may not have been detectable in the field, where many interacting variables influence bacterial population sizes. Alternatively, the strains Pf-5 and 122 may differ in their capacities to establish themselves in protected sites on leaf surfaces, where RpoS may not be critical to bacterial survival. Furthermore, if stress response is an absolute requirement for survival on leaves, then an epiphytic bacterium such as strain 122 may secure its survival by possessing redundant regulatory mechanisms that ensure the expression of stress response genes when and where they are needed. The involvement of multiple sigma factors in stress response of $P$. fluorescens $(22,27)$ provides an example of this redundancy but the relative importance of these factors in strains from different microbial habitats has not yet been explored. The findings of this and the accompanying study (4) indicate that RpoS has a minor role in stress response of epiphytic strains of Pseudomonas spp. Therefore, plant-associated epiphytes such as P. fluorescens strains 122 or A506 may be excellent candidates for further study of RpoS-independent mechanisms of environmental stress response.

\section{ACKNOWLEDGMENTS}

This research was supported in part by grant 95-37312-1655 from the U.S. Department of Agriculture (USDA) Cooperative State Research, Education, and Extension Service, National Research Initiative-Competitive Grants Program, Biologically-Based Pest Management Program, and by the USDA-Agricultural Research Service CRIS project 535812220-002-00D. We thank M. Henkels and B. Shaffer for excellent technical assistance.

\section{LITERATURE CITED}

1. Beattie, G. A., and Lindow, S. E. 1995. The secret life of foliar bacterial pathogens on leaves. Annu. Rev. Phytopathol. 33:145-172.

2. Burrage, S. W. 1976. Aerial microclimate around plant surfaces. Pages 173-184 in: Microbiology of Aerial Plant Surfaces. C. H. Dickinson and T. F. Preece, eds. Academic Press, Inc., New York.

3. Garrity, G. M., Brenner, D. J., Krieg, N. R., and Staley, J. R., eds. 2005. The Proteobacteria. Part B. The Gammaproteobacteria, 2nd ed. Bergey's Manual of Systematic Bacteriology, Vol. 2. Springer, New York.

4. Hagen, M. J., Stockwell, V. O., Whistler, C. A., Johnson, K. B., and Loper, J. E. 2009. Stress tolerance and environmental fitness of Pseudomonas fluorescens A506, which has a mutation in rpoS. Phytopathology 99:679-688.

5. Heeb, S., Valverde, C., Gigot-Bonnefoy, C., and Haas, D. 2005. Role of the stress sigma factor RpoS in GacA/RsmA-controlled secondary metabolism and resistance to oxidative stress in Pseudomonas fluorescens CHA0. FEMS Microbiol. Lett. 243:251-258.

6. Hengge-Aronis, R. 2002. Recent insights into the general stress response regulatory network in Escherichia coli. J. Mol. Microbiol. Biotechnol. 4:341-346.

7. Hengge-Aronis, R. 2002. Signal transduction and regulatory mechanisms involved in control of the sigma(S) (RpoS) subunit of RNA polymerase. Microbiol. Mol. Biol. Rev. 66:373-395.

8. Hilario, E., Buckley, T. R., and Young, J. M. 2004. Improved resolution on the phylogenetic relationships among Pseudomonas by the combined analysis of $\operatorname{atp} \mathrm{D}, \operatorname{car} \mathrm{A}, \operatorname{rec} \mathrm{A}$ and $16 \mathrm{~S}$ rDNA. Antonie Leeuwenhoek 86:51-64.

9. Johnson, K. B., and Stockwell, V. O. 1998. Management of fire blight: a case study in microbial ecology. Annu. Rev. Phytopathol. 36:227-248.

10. Jørgensen, F., Bally, M., Chapon-Herve, V., Michel, G., Lazdunski, A., Williams, P., and Stewart, G. S. A. B. 1999. RpoS-dependent stress tolerance in Pseudomonas aeruginosa. Microbiology 145:835-844.

11. Kim, Y., Watrud, L. S., and Matin, A. 1995. A carbon starvation survival gene of Pseudomonas putida is regulated by $\sigma^{54}$. J. Bacteriol. 177:18501859.

12. King, E. O., Ward, M. K., and Raney, D. E. 1954. Two simple media for the demonstration of pyocyanin and fluorescein. J. Lab. Clin. Med. 44:301-307.

13. Kojic, M., Degrassi, G., and Venturi, V. 1999. Cloning and characterisation of the rpoS gene from plant growth-promoting Pseudomonas putida WCS358: RpoS is not involved in siderophore and homoserine lactone production. Biochem. Biophys. Acta. 1489:413-420.

14. Lindow, S. E., Andersen, G., and Beattie, G. A. 1993. Characteristics of 
insertional mutants of Pseudomonas syringae with reduced epiphytic fitness. Appl. Environ. Microbiol. 59:1593-1601.

15. Lindow, S. E., and Brandl, M. T. 2003. Microbiology of the phyllosphere. Appl. Environ. Microbiol. 69:1875-1883.

16. Miller, C. D., Kim, Y.-C., and Anderson, A. J. 2001. Competitiveness in root colonization by Pseudomonas putida requires the rpoS gene. Can. J. Microbiol. 47:41-48.

17. Miller, C. D., Mortensen, W. S., Braga, G. U. L., and Anderson, A. J. 2001. The rpoS gene in Pseudomonas syringae is important in surviving exposure to the near-UV in sunlight. Curr. Microbiol. 43:374-377.

18. Miura, K., Inouye, S., and Nakazawa, A. 1998. The rpoS gene regulates $\mathrm{OP} 2$, an operon for the lower pathway of xylene catabolism on the TOL plasmid, and the stress response in Pseudomonas putida mt-2. Mol. Gen. Genet. 259:72-78.

19. Ngugi, H. K., and Scherm, H. 2006. Biology of flower-infecting fungi. Annu. Rev. Phytopathol. 44:261-282.

20. Nyström, T. 2004. Stationary-phase physiology. Annu. Rev. Microbiol. 58:161-181.

21. Paulsen, I. T., Press, C. M., Ravel, J., Kobayashi, D. Y., Myers, G. S. A., Mavrodi, D. V., DeBoy, R. T., Seshadri, R., Ren, Q., Madupu, R., Dodson, R. J., Durkin, A. S., Brinkac, L. M., Daugherty, S. C., Sullivan, S. A., Rosovitz, M. J., Gwinn, M. L., Zhou, L., Schneider, D. J, Cartinhour, S. W., Nelson, W. C., Weidman, J., Watkins, K., Tran, K., Khouri, H., Pierson, E. A., Pierson, L. S., III, Thomashow, L. S., and Loper, J. E. 2005. Complete genome sequence of the plant commensal Pseudomonas fluorescens Pf-5: insights into the biological control of plant disease. Nat. Biotechnol. 23:873-878.

22. Péchy-Tarr, M., Bottiglieri, M., Mathys, S., Lejbølle, K. B., SchniderKeel, U., Maurhofer, M., and Keel, C. 2005. RpoN $\left(\sigma^{54}\right)$ controls production of antifungal compounds and biocontrol activity in Pseudomonas fluorescens CHA0. Mol. Plant-Microbe Interact. 18:260272.

23. Ramos-González, M. I., and Molin, S. 1998. Cloning, sequencing, and phenotypic characterization of the rpoS gene from Pseudomonas putida
KT2440. J. Bacteriol. 180:3421-3431.

24. Sambrook, J., Mac Callum, P., and Russell, D. 2001. Molecular Cloning: A Laboratory Manual. Cold Spring Harbor Laboratory Press, Cold Spring Harbor, NY.

25. Sanzol, J., Rallo, P., and Herrero, M. 2003. Asynchronous development of stigmatic receptivity in the pear (Pyrus communis; Rosaceae) flower. Am. J. Bot. 90:78-84

26. Sarniguet, A., Kraus, J., Henkels, M. D., Muehlchen, A. M., and Loper, J. E. 1995. The sigma factor $\sigma^{\mathrm{S}}$ affects antibiotic production and biological control activity of Pseudomonas fluorescens Pf-5. Proc. Natl. Acad. Sci. USA 92:12255-12259.

27. Schnider-Keel, U., Lejbølle, K. B., Baehler, E., Haas, D., and Keel, C. 2001. The sigma factor AlgU (AlgT) controls exopolysaccharide production and tolerance towards desiccation and osmotic stress in the biocontrol agent Pseudomonas fluorescens CHA0. Appl. Environ. Microbiol. 67:5683-5693.

28. Schuster, M., Hawkins, A. C., Harwood, C. S., and Greenberg, E. P. 2004. The Pseudomonas aeruginosa RpoS regulon and its relationship to quorum sensing. Mol. Microbiol. 51:973-985.

29. Stockwell, V. O., Johnson, K. B., and Loper, J. E. 2002. Antibiosis contributes to biological control of fire blight by Pantoea agglomerans strain Eh252 in the field. Phytopathology 92:1202-1209.

30. Stockwell, V. O., and Loper, J. E. 2005. The sigma factor RpoS is required for stress tolerance and environmental fitness of Pseudomonas fluorescens Pf-5. Microbiology 151:3001-3009.

31. Suh, S.-J., Silo-Suh, L., Woods, D. E., Hassett, D. J., West, S. E. H., and Ohman, D. E. 1999. Effect of rpoS mutation on the stress response and expression of virulence factors in Pseudomonas aeruginosa. J. Bacteriol. 181:3890-3897.

32. Uwate, W. J., and Lin, J. 1981. Development of the stigmatic surface of Prunus avium L., sweet cherry. Am. J. Bot. 68:1165-1176.

33. Whistler, C. A., Stockwell, V. O., and Loper, J. E. 2000. Lon protease influences antibiotic production and UV tolerance of Pseudomonas fluorescens Pf-5. Appl. Environ. Microbiol. 66:2718-2725. 